\title{
The coupling between devaluation of writing in scientific authorship and inflation of citation indices
}

Terry Engelder, Department of Geosciences, The Pennsylvania State University, University Park, Pennsylvania 16827, USA

Traditionally, scientific authorship was earned by those who contributed to the intellectual enterprise of a paper through writing and rewriting. Like the effect of grade inflation on the value of A-grades awarded at the top research universities, the act of writing as a prerequisite for authorship in the geosciences literature has rapidly evolved over the past three decades. An analysis of authorship of Geology papers illustrates this evolution. With its inaugural issues in late 1973, the standard for authorship was set at 1.9 authors per paper with $46 \%$ of all Geology papers written by single authors the mode that first year (Fig. 1). Less than 10\% of these 1973 papers claimed more than three authors. The source of intellectual input into the communication of scientific discovery was clear during the early history of Geology.

After 1973, the average number of authors per paper continued to rise steadily. By the mid-1980s, the mode for authorship in Geology shifted to two, a number that remains the mode to this day. As much as anything, this mode reflects writing shared between graduate student and mentor. Sometime later, in the 1990s, the average number of authors per paper in Geology exceeded three. During the latter half of 2006, the average number of authors per paper broke above four, a level of authorship where the source of intellectual input through writing becomes unclear. In the 2006 sample, only 3\% of all Geology papers were written by a single author, and the percentage of first authors also dropped to an all-time low.

Aside from a devaluation of writing as a prerequisite for authorship in Geology papers, what does all this mean?

The trend in authorship for Geology papers seems to correlate with the tilt of earth science toward multidisciplinary collaboration. Indeed, the National Science Foundation developed the capability for principal investigators to submit collaborative proposals in response to the scientific community's desire to submit such proposals (D. Fountain, 2007, personal commun.). Big science does require the integration of outputs from a number of laboratories, and these should be recognized. The trend in authorship also correlates with the proliferation of crossborder projects, particularly those focused on the Himalayans, the Andes, and other areas. Multi-government funding of large programs in the oceans and in space also contributed to this
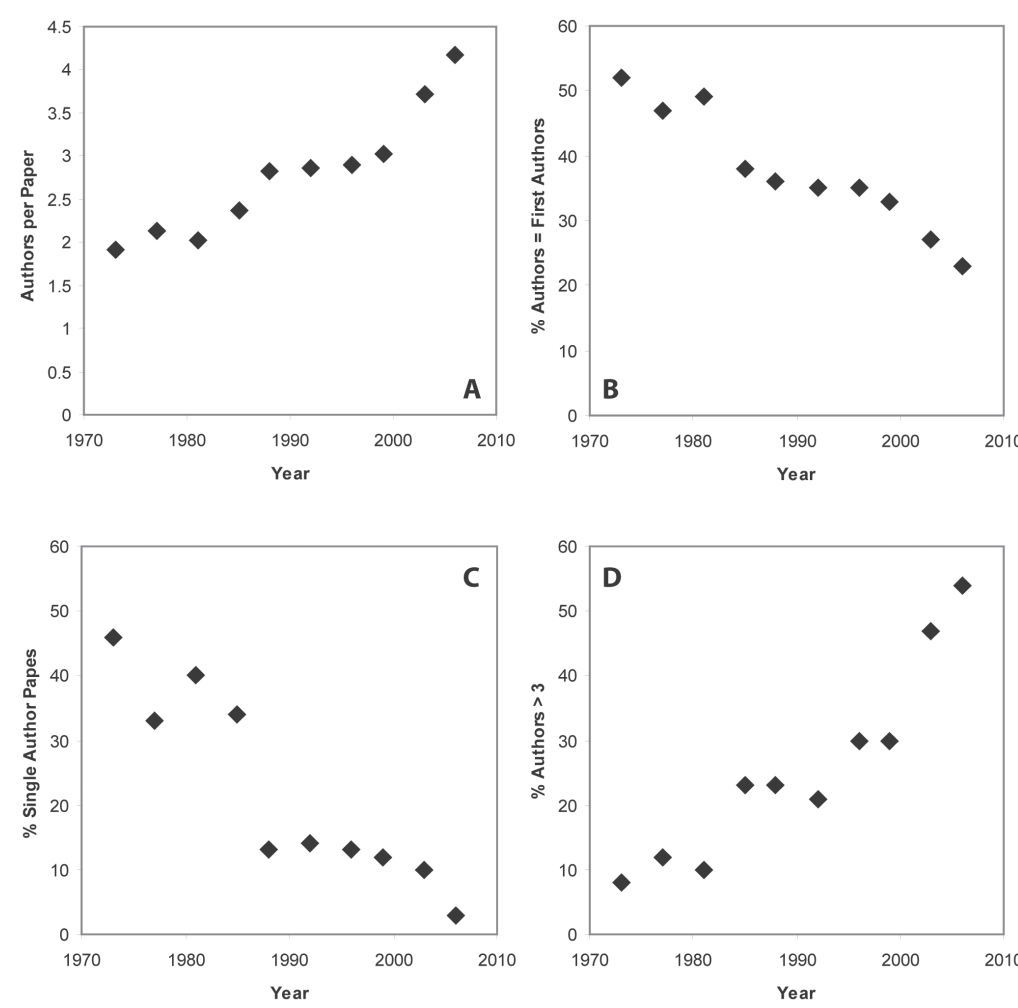

Figure 1. Data on authorship in samples of papers published in Geology since its inception in 1973. With the exception of the 1973 sample, all other samples are from six-month or twelve-month periods depending on which sample yielded between 100 and 150 papers, thereby normalizing the number of papers from year to year. The six-month samples were arbitrarily selected within the publication year. Large-project papers were binned according to the number of authors listed in the contents of each issue. (A) Average number of authors per Geology paper from a sample of between 100 and 150 papers. (B) Percentage of first authors in the total author pool. (C) Percentage of single-author papers. (D) Percentage of authors who were not listed as one of the first three authors in the total author pool. 
trend. By scientific etiquette, the results of each of these types of projects require broad recognition. The question is whether this recognition should come through citations or through the addition of names to the authorship lists that in Geology have reached as high as 14 as of late.

The trend in authorship in Geology reflects the vitality of the earth sciences as political borders and project size are no longer the obstacles they once were. It is equally vital for the science to take advantage of many data sets, some of which require very expensive machines to gather. However, there is an issue about whether the intellect of the individual is being squeezed out by "big" science as we move into the twenty-first century. One interpretation of the authorship data from papers published in Geology is that there is far less individual initiative, at least in terms of writing, than there was 30 years or more ago. This trend (i.e., the devaluation of writing as a prerequisite for authorship) is of concern, in part because the trend signals the diminution of the solitary thinker and writer. After all, writing is a major component of intellectual enterprise leading to good science, and writing is less effective when the committee of writers and rewriters grows beyond a very low number.

A corollary to the devaluation of writing in scientific discovery is the inflation of citation indices. Under the present system, for a 14-author Geology paper cited once, each author will claim that citation in his or her personal citation index. That paper increments 14 citation indices once and thus has the same effect as 14 citations of a single-author Geology paper where the single author has his index incremented 14 times. The hardest part of scientific discovery is the communication aspect, yet in a 14-author Geology paper, communication, usually the first author's responsibility, is given no greater reward that that received by the fourteenth author. It seems that the next best mechanism for padding citation indices beyond selfcitation is to join a number of multi-author papers.

To correct the dual predicament of devaluation of writing in scientific authorship and inflation of citation indices, I draw a distinction between the present citation index, where each author claims a citation independently of the number of authors and citation credit (value of a particular paper normalized by the number of authors) plus citation credit index (citation credit multiplied by the number of citations). To the best of my knowledge, the terms citation credit and citation credit index are new to the literature. I suggest that each paper be awarded a maximum of two citation credits per paper with the first author always earning one credit per citation. A second credit would be divided evenly among the secondary authors. Thus, in the typical 14-author Geology paper, each of the secondary authors earns a 0.08 credit per citation for the paper, and this would be the number claimed by secondary authors on their annual promotion and tenure or salary review dossiers and other documents of self-congratulation. In a two-author Geology paper, each author would earn one credit per citation, thereby allowing a thesis advisor to earn his or her just due for preparing a thesis for publication when the graduate student disappears into some job that does not reward publication. With this citation credit algorithm, communication of scientific discovery would be restored to its proper position in the reward hierarchy of the geoscience community.
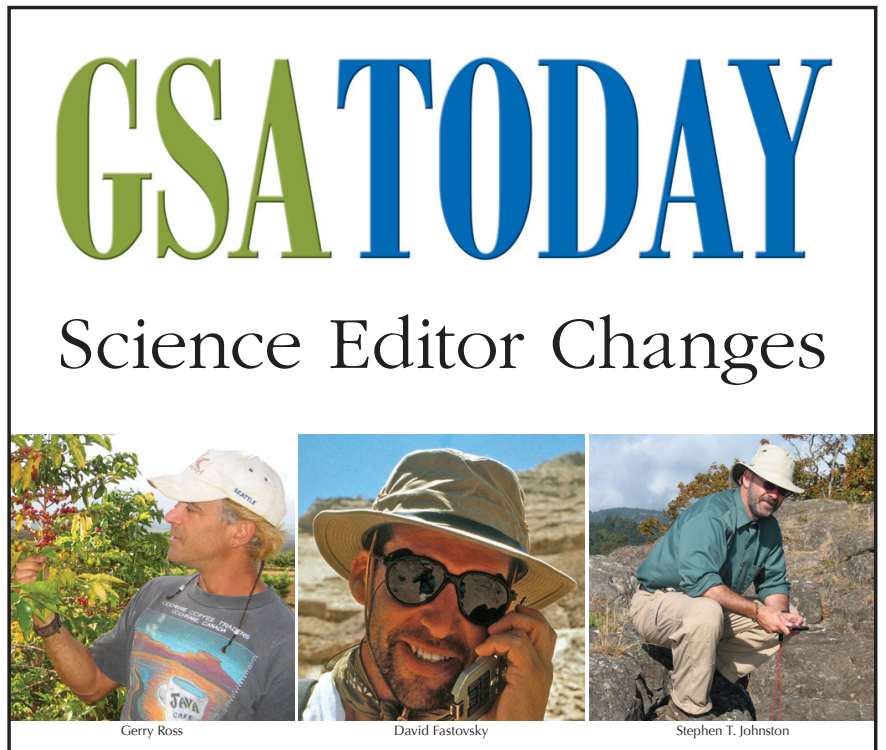

Gerry Ross has completed his term and then some as GSA Today science co-editor. Ross will keep his hat in the geoscience arena by following an earth systems approach to the application of the principles of soil science, aqueous geochemistry, and geomicrobiology to organic agriculture on his farm in Maui. GSA Pubs will miss working with you, Gerry!

David Fastovsky, a GSA Fellow familiar to many, steps in as GSA Today's new science co-editor. Fastovsky received the GSA Distinguished Service Award last year after several years as Geology editor (1999-2005), service on numerous GSA committees, and work as associate editor on GSA Bulletin (1996-2000).

Science co-editor Stephen T. Johnston, who began his term last year, continues his quest "to bring forward highquality articles that appeal to as broad an audience as possible and that spark debate within our community regarding the major societal and scientific questions facing the earth sciences."

GSA Today science editors are charged with obtaining first-class, focused articles that collectively reflect and summarize current topics and discoveries in the earth sciences. Science editors also solicit "Groundwork" articles, GSA Today's newest article series, meant to further the influence of earth science on education, policy, planning, and funding. All submissions, whether solicited or volunteered, are reviewed. To submit a science or Groundwork article to GSA Today, send your manuscript and figures via e-mail directly to Stephen Johnston, stj@uvic.ca, and David Fastovsky, defastov@uri.edu.

Editor's Note: The following guideline applies to all Geology submissions: "For multi-author papers, Geology editors expect that all the authors have been involved with the work, have approved the manuscript, and agree to its submission. A statement on the respective roles of each author when more than five authors are listed is required." 